\title{
LÁGRIMAS SALGADAS: UMA ANÁLISE SOBRE O POEMA MAR PORTUGUÊS DE FERNANDO PESSOA E O REFÚGIO SÍRIO PELO MAR MEDITERRÂNEO
}

\section{SALT TEARS: AN ANALYSIS OF THE POEM PORTUGUESE SEA OF FERNANDO PESSOA AND THE SYRIAN REFUGE BY THE MEDITERRANEAN SEA}

\author{
Isabela Vieira Barbosa \\ Mestranda em Educação da Universidade Regional de Blumenau \\ Pós-Graduado em Educação Infantil e Desenvolvimento pela Universidade Cândido Mendes \\ E-mail: miss.vieira@gmail.com \\ Patricia Pires Thomazelli \\ Mestranda em Educação da Universidade Regional de Blumenau \\ Especialista em Dança Educacional pela Faculdade São Fidelis \\ E-mail: patriciapt.dance@gmail.com \\ Adolfo Ramos Lamar \\ Doutor em Educação pela Universidade Estadual de Campinas \\ Mestre em Política Científica e Tecnológica pela Universidade Estadual de Campinas \\ E-mail: ajemabra@yahoo.com.br
}

\section{RESUMO}

O objetivo deste trabalho é analisar o poema "Mar Português" do autor Fernando Pessoa com o refúgio sírio pelo Mar Mediterrâneo. Através dessa análise, pretendemos relacionar alguns pensamentos recorrentes nas publicações sobre o fluxo migratório do século XXI e os pensamentos do autor sobre o fluxo migratório no período das grandes navegações. Desta forma, através de uma pesquisa bibliográfica, iremos abordar os pensamentos do autor português à época das grandes navegações e os relatos encontrados, com as noticias e relatos da crise migratória atual. A partir deste estudo concluímos que, apesar dos sofrimentos e das dificuldades serem incomparáveis, percebem-se semelhanças nas dificuldades encontradas em ambas as situações, bem como nos relatos de sobreviventes e nos descumprimentos aos direitos humanos.

Palavras-chave: Imigração. Sofrimento. Refugiados.

\section{ABSTRACT}

The objective of this work is to analyze the poem "Portuguese Sea", by the author Fernando Pessoa, with the Syrian refuge by the Mediterranean Sea. Through this analysis, we intend to relate some recurrent thoughts in the publications about the migratory flow of the $21^{\text {st }}$ century 
and the thoughts of the author on the migratory flow in the period of the great navigations. Thus, through a bibliographical research, we will approach the thoughts of the Portuguese author at the time of the great navigations and the reports found, with the news and reports of the current migratory crisis. From this study, we conclude that, despite the sufferings and difficulties being incomparable, we can see similarities in the difficulties encountered in both situations, as well as in the reports of survivors and in the noncompliance with human rights.

Key-words: Immigration. Suffering. Refugees.

\section{BEM VINDOS AO MAR!}

O foco desta análise é criar um espaço em que possamos refletir e estabelecer uma relação entre o poema "Mar Português" do autor lusitano Fernando Pessoa, e a situação dos refugiados sírios. Diante da presença de uma guerra civil onde seu país se encontra e a iminência do Estado Islâmico, muitos tentam fugir para a Europa Ocidental em busca de sobrevivência e talvez uma maior segurança.

Perante a grande comoção a qual a mídia tem destacado ao tema, além dos frequentes debates em órgãos internacionais como na ONU, e organizações não governamentais como Médicos Sem Fronteiras, entre outras, identificamos que este tema possui um grande valor e relevância social para a comunidade cientifica para entendermos o contexto o qual tal povo está sendo vitimado por tamanhas atrocidades, principalmente no neste contexto atual onde se discute os direitos humanos e percebe-se que existe um movimento imigratório que quer evidenciar as dificuldades de acesso aos direitos dos refugiados. Lembramos também, que tal assunto é de grande relevância perante a sociedade que após diversos conflitos civis e militares, busca constantemente compreender melhor a relação entre tais eventos e as crises humanitárias.

Assim, ao analisar os relatos jornalísticos acerca do fluxo migratório árabe nos últimos anos, recordamos histórias migratórias que fizeram parte da história de todos os povos, com diferentes tipos de confronto, colocando diversos desafios à própria vida dos sujeitos. Por todas essas razões, o optamos em destacar o poema do poeta lusitano Fernando Pessoa, "Mar Português" por abordar o tema do período das grandes expansões marítimas portuguesas, recordando e destacando-o como um dos períodos turbulentos da história das navegações: a abertura de novas rotas.

Ó mar salgado, quanto do teu sal

São lágrimas de Portugal!

Por te cruzarmos, quantas mães choraram,

Quantos filhos em vão rezaram!

Quantas noivas ficaram por casar 


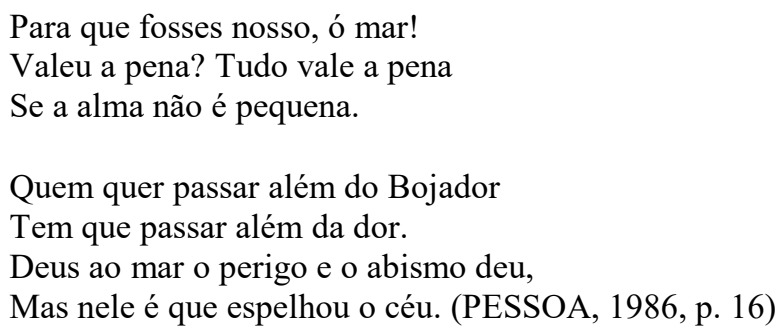

Neste sentido, o poema "Mar Português" será aqui relacionado com a situação dos refugiados no sentido de acompanhar a liquidez das informações relacionadas a esta temática de uma forma mais sensível. A partir disto, podemos compreender que a ideia do poema inspirado na expansão territorial portuguesa, marcada por diversas dificuldades pode muito bem se aplicar também as novas dificuldades encontradas no processo migratório imposto ao povo sírio.

Cumpre referir que nesta perspectiva, esta pesquisa será bibliográfica e documental, tendo em vista, que será realizada uma análise do poema "Mar Português". Este poema retrata o contexto histórico das grandes navegações portuguesas que ocorreram nos séculos XV e XVI, em busca de novas rotas comercias pelo povo lusitano em suas estrofes, entretanto destaca também as dificuldades do percurso que navegadores e suas respectivas famílias encontravam além mar. Apesar de muitas vezes as famílias não desbravarem o oceano e irem à busca de uma nova oportunidade do outro lado do oceano, eram elas que muitas vezes enfrentavam as sombras das dificuldades. Famílias separadas, viúvas, órfãos e familiares que perdiam não só seus entes queridos, mas muitas vezes também a sua fonte de renda.

Em consonância ao fato histórico, será feita uma contextualização dos versos com a situação atual da Síria e seus refugiados, os quais estão fugindo para a Europa Ocidental em busca de sobrevivência. Não buscamos aqui de forma alguma, comparar o sofrimento ou a gravidade das duas diferentes razões que os levaram a atravessar o mar, mas sim, analisar de que forma o poema do autor pode se relacionar com o sentimento de desbravamento que tais povos em momentos tão distintos acabaram por optar pela mesma situação.

O marco central para a conclusão deste trabalho se apresenta na reflexão sobre as dores físicas e emocionais as quais estas pessoas durante as imigrações e nas situações de fronteira se enfrentam atualmente.

\section{MAR A VISTA!}

O poema escrito em 1934 versa sobre algumas das maiores conquistas em um dos períodos mais turbulentos da história das navegações. Este poema será uma base para interpretação na qual buscamos refletir sobre a situação atual dos sírios que vivem em situação de fronteira e imigração. 
Posto isso, buscaremos a partir de cada estrofe fazer uma reflexão assimilando os pontos em comum com o contexto encontrado. Neste sentido no decorrer deste texto "Mar à vista!" traçaremos uma relação com base na primeira estrofe que versa o poema de Fernando Pessoa.

Quando Pessoa fala "Ó Mar salgado, quanto do teu sal, são lágrimas de Portugal! Por te cruzarmos, quantas mães choraram quantos filhos em vão rezaram!” (PESSOA, 1986, p.16). Podemos desta forma, tirar duas ou até mais interpretações deste verso! A primeira é que o autor se remete as dificuldades físicas e psicológicas as quais portugueses foram infligidos diante das travessias e das expansões territoriais que buscavam suas novas rotas.

A segunda é que se remete ao mar como o Mar "de" Portugal no sentido de demarcação de território. Por isso, "A questão se refere às grandes navegações que serviram para transformar o mar em coisa portuguesa: ó mar salgado, quanto do teu sal são lágrimas de Portugal" (FONSECA, 2006, s.p.)

Entretanto, falaremos com base na primeira hipótese, a qual nos remete novamente a interpretação do verso para as dificuldades psicológicas. Como adiante ficará suficiente demonstrado, não nos gastaremos aqui em explanar as dificuldades naturais que os navegadores enfrentaram como ventos contrários e naufrágios. Contudo, tentaremos expressar a dor que essas travessias causaram no âmago das famílias e da humanidade.

O poeta se pergunta de forma figurativa, quanto do sal do mar, não seria parte da amarga dor das incertezas do caminho e das aflições infligidas àqueles que ousaram não só o mar enfrentar, mas a um novo mundo descobrir.

Todos os seres humanos passam por experiências dolorosas que resultam em lágrimas de dor e medo que imerge no ser - lágrimas salgadas! Muitas vezes devido às dificuldades emocionais e físicas as quais nos submetemos. Entretanto existem diversas situações que poderíamos dizer quase impossíveis de não afundar em dor e medo, sendo submetido nessas circunstâncias. O medo e a dor de perder a sua vida e de seus entes queridos!

\footnotetext{
O medo não é uma emoção patológica, mas algo universal dos animais superiores e do homem. O medo é um estado de progressiva insegurança e angústia, de impotência e invalidez crescentes, ante a impressão iminente de que sucederá algo que queríamos evitar e que progressivamente nos consideramos menos capazes de fazer. (D'ELIA, 2006, p.1 apud DALGALARRONDO, 2006, p. 109)
}

Hoje, ao analisarmos a coragem e o atrevimento em busca de uma nova vida em terras distantes, encontramos um pensamento característico aos navegantes portugueses e aos navegantes sírios. Nota-se que, mesmo diante das diferenças temporais as quais tais povos se 
encontravam, e as dificuldades as quais ambos enfrentavam, observamos milhares de pessoas que ao mar se lançam, deixando em seus países de origem saudades e sofrimento na esperança de tempos melhores.

Lançando suas sortes ao mar, arriscando nas incertezas, cheios de esperanças, porém muitas vezes preenchendo os mares com suas lágrimas de sofrimento ou de alívio. Nem sempre correspondidas.

Durante a era das navegações, o mar era opção portuguesa, pois o estranho era instigador, e ao mesmo tempo surgia a necessidade de expandir as negociações comerciais, conforme autores como Diegues (2010), Tengarrinha (2001) e Silva (1989) ressaltam.

O poema de Fernando Pessoa é um retrato desta época em que aconteciam as navegações de expansão territorial, e uma das características apontadas é a questão do medo. Neste sentido o autor Luís Adão da Fonseca, nos mostra em seu artigo "O imaginário dos navegantes portugueses dos séculos 15 e 16" alguns exemplos sobre como o medo infligia o homem naquele tempo e espaço.

Tal é portanto, a segunda idéia que gostaria de sublinhar: no conjunto do imaginário oceânico medieval, o imaginário atlântico comporta forte dimensão, tanto do não conhecido como do adverso, destruidor, perigoso. As raízes culturais desta convicção remontam, em parte, ao texto bíblico e às fontes da antigüidade, mas reportam-se também às elucubrações da ciência da época. Em certa medida, o oceano está associado à idéia do medo; com efeito, ele é o espaço aberto de onde - para além de certo limite é impossível regressar. (FONSECA, 1992, p.42)

Agora, é necessário destacarmos aqui o medo dos sírios que estão sendo obrigados pelo medo do confronto a deixar suas terras e fugir. Lembramos que a fuga marítima não tem sido a única opção, muitos sírios tem buscado nos seus países vizinhos abrigo, fugindo por terra também. Porém, queremos aqui destacar a dramaticidade das fugas marítimas, tendo em vista que as dificuldades encontradas resultam não apenas em momentos dramáticos, mas tendo resultado principalmente em uma quantidade de mortes poucas vezes vistas na história da humanidade. De acordo com a Organização Internacional de Migração, OIM, no ano de 2013, 700 imigrantes morreram tentando fazer tal travessia, no ano de 2014 já eram 3.200 e em apenas 4 meses de 2015, já somava-se mais de 2.000 mortos.

Nos dias atuais, não são mais os diários de viagens, como o de Pero Vaz de Caminha, ou Vasco da Gama que narram as tragédias e as condições precárias as quais tais navegantes se submetem. São os imigrantes sírios com seu smartphones e aparelhos modernos que estão a deixar registrados na humanidade um dos maiores movimentos de imigração já acontecidos. É por causa da guerra que os civis têm de deixar seu lar, é por causa da guerra que os sírios têm de 
arriscar suas vidas no mar. Não é difícil imaginar o quanto essa situação provoca o medo nas pessoas. Temos como exemplo a imagem que calou o mundo da menina síria que se rendeu contra a câmera fotográfica da repórter Nadia Abu Shaban quando a confundiu com uma arma. Imagem de doer os olhos e a alma de quem a vê foi posta no Twitter da fotografa:

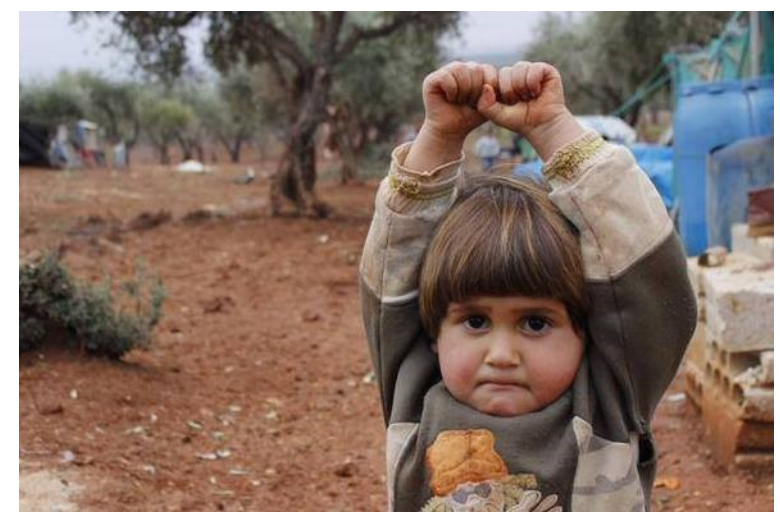

Figura 1: Nadia Abu Shaban

Fonte: Twitter

Demonstrando que apesar dos muitos séculos de distância, das invenções modernas e da distância geográfica entre a Síria e Portugal, a fragilidade diante das incertezas, das privações e do próprio medo em muito se assemelham, mesmo quando a única opção remanescente é a mesma: lançar-se ao mar.

\section{MAR DE LÁGRIMAS!}

Na segunda estrofe lemos, "Quantas noivas ficaram por casar, Para que fosses nosso, ó mar! Valeu a pena? Tudo vale a pena, Se a alma não é pequena.” (PESSOA, 1986, P.16)

Pessoa segue com o pensamento que o cruzar do Atlântico representava mais do que um simplesmente cruzamento geográfico, significava a oportunidade de criar novas rotas, expandir o "Velho Mundo" em um mundo de oportunidades e possibilidades. Mesmo que como pagamento dessa busca muitas famílias ficassem órfãs e esposas viúvas.

As rotas buscadas pelos navegadores lusitanos representavam mais do que apenas uma expansão comercial, era a possibilidade de uma expansão territorial que seria capaz de estabilizar e fortalecer Portugal. Eram novos mercados para exploração, produção e reprodução, e acima de tudo, novas possibilidades para toda população.

Talvez o melhor exemplo que possamos utilizar para ilustrar como essa dificuldade possa ser relacionado ao sofrimento prescrito aos familiares desses imigrantes, seja a triste história do menino Aylan Kurdi. 
O pequeno menino sírio de apenas 3 anos, foi a vítima símbolo dessa imigração desesperada, por tantas famílias que buscam sobreviver aos conflitos em seu país de origem e ao terror imposto pelo Estado Islâmico. Depois de vagar e fugir por diversos países elas tenta a sorte lançando-se ao mar. Pai, mãe e dois filhos. Buscavam a Europa, como uma chance de sobreviver, já que o Canadá, país onde sua família vivia não os aceitaram como refugiados.

O sofrimento infligido a mais essa família imigrante, tal como muitas portuguesas nos séculos XV e XVI abriu os olhos para os direitos humanos negligenciados desses refugiados, que em uma nova crise internacional fixa mais uma diáspora ${ }^{1}$. A Organização das Nações Unidas em seu primeiro parágrafo da Declaração Universal dos Direitos Humanos destaca que "Todas as pessoas nascem livres e iguais em dignidade e em direitos. São dotadas de razão e de consciência e devem agir em relação uma às outras com espírito de fraternidade." Porém, ao nos deparamos com o sofrimento infligido ao povo sírio, refletimos sobre as avançadas legislações que surgiram muito depois da Era das Navegações, mas que ainda encontram obstáculos para efetivamente aplacar tais dores.

Hoje, vivemos outra diáspora, uma dispersão de parte do povo árabe, especialmente de origem síria, em consequência da perseguição da região político-religiosa do Estado Islâmico.

A temida organização criminosa, intitulada Estado Islâmico, antes conhecida como EIIL - Estado Islâmico do Iraque e do Levante, é formada por um grupo armado sunita radical contrario ao governo do ditador sírio Bashar Al Assad. Favorecido pela divisão de xiitas e sunitas iraquianos e sírios que tenta impor uma visão ultraconservadora do Irã, contra povos pelos quais possui ódio: Estados Unidos, Irã, em um menor grau a Europa e principalmente minorias étnicas. Desde o inicio do seu levante, o Estado Islâmico tem atuado especialmente na Síria e no Iraque. Entretanto, o que tem dado tanto destaque a tal grupo terrorista, é a brutalidade dos métodos de tortura e assassinato utilizados contra as vítimas do grupo, nem sempre militares e membros do governo.

No meio desse confronto encontra-se a população síria, que é vítima dos bombardeios frequentes às principais cidades e o confronto direto entre o governo do ditador Bashar al-Assad, os terroristas do Estado Islâmico e também dos rebeldes ${ }^{2}$. Estima-se que até setembro de 2015, os países vizinhos da Síria, tais como Turquia, Líbano e Jordânia tenham recebido mais de 3,6 milhões de refugiados, (BBC, 2015) sem contar os 381.412 imigrantes que até o dia 7 de setembro haviam chegado a Europa (G1, 2015).

O autor na frase mais célebre do poema Mar Português questiona "Valeu a pena?" e continua "Tudo vale a pena, Se a alma não é pequena". Porém, aqui problematizamos, será que realmente vale a pena? 
Algumas pessoas destacariam que diante da atrocidade vivenciada pelos povos sírios no meio de tantas batalhas, bombardeios e precariedade, talvez enfrentar o mar seja apenas mais um obstáculo em busca de um futuro melhor. Talvez alguém ainda questione que para os portugueses a travessia do Cabo Bojador era apenas um obstáculo entre Portugal estagnado e um futuro possivelmente proeminente.

No entanto, se levarmos em consideração apenas a frase "Tudo vale a pena" poderíamos citar diferentes passagens históricas e frases célebres que usaram a mesma prerrogativa para justificar fins não tão justos como a imigração. Adolf Hitler, por exemplo, em um de seus discursos tentou justificar-se dizendo que "Todos os representantes da classe culta polonesa, portanto, têm de ser exterminados. Isso parece crueldade, mas é a lei da vida." Enquanto provocava o que é considerado até hoje a maior crise migratória da humanidade, seguida pelo maior crime contra a humanidade: o extermínio dos judeus. O genocídio de Uganda poderia ser outro exemplo, que justificando uma máxima maquiavélica de que "os fins justificam os meios", provocou novamente a morte de mais de 800 mil pessoas, e outra crise migratória, dos tutsis que fugiam em busca de sobrevivência.

Pessoa talvez por isso termine a frase com a afirmação de que tudo valerá a pena, apenas se a alma não for pequena. No sentido não de tamanho, mas que seja madura nobre e generosa, fugindo das pequenezas da mesquinharia.

\section{UM MAR TRAIÇOEIRO!}

O poema de Fernando Pessoa faz menção ao Cabo Bojador, na terceira estrofe do poema. Pessoa remete ao fato histórico da travessia ao versar que, "Quem querer passar além do Bojador, Tem que passar além da dor. Deus ao mar o perigo e o abismo deu, Mas nele é que espelhou o се́u” (PESSOA, 1986, p.16).

Não podemos realizar uma comparação direta do contexto ao quais as pessoas emigravam de Portugal e Síria, pois eram diferentes. De Portugal saíram os grandes navegadores em busca de novas rotas comerciais, pois as rotas do mediterrâneo estavam prejudicadas. Não havia guerra civil em Portugal e em quase totalidade das vezes, não iam famílias inteiras. Já na Síria o país está devastado pela guerra civil, aonde famílias inteiras são obrigadas a se refugiar em outros países. Afundando-se na tristeza de sair da sua terra para outra. Apesar dessas diferenças, encontramos uma grande semelhança entre esses dois países: a dificuldade de superar o medo e a travessia! 
Neste sentido, nos respaldamos nestes dois fatos históricos - a travessia do Cabo Bojador e a travessia pelo Mar Mediterrâneo - comparando essas dificuldades. Essas dificuldades serão explicitas pela pesquisa feita em documentos acadêmicos e jornalísticos. Adiante nos direcionaremos ao termo "mar traiçoeiro", termo utilizado devido ao fato de falarmos aqui de dois mares que possivelmente causaram a morte de centenas de pessoas.

O Cabo Bojador apresenta uma passagem de difícil cruzada em que pela primeira vez Gil Eanes dobrou o medo 1434 (CUYVERS, 1998). Eanes foi o primeiro a cruzar o Cabo Bojador, o qual é uma passagem na costa da África em que existem muitos corais e pedras. Em certos períodos do trajeto a profundidade do mar chega a atingir dois metros o que dificulta a passagem dos marinheiros com suas caravelas. Os que se arriscavam neste mar corriam o risco do naufragar com toda a sua mercadoria, além de correr o risco de morte.

Com efeito, traremos o significado da palavra Bojador a qual a situamos em Fonseca (2006, p.1) "E palavra Bojador? Diz Silveira Bueno que vem do holandês "bogen" que gerou o verbo português "bojar", ou seja, a manobra do navio percorrendo a costa ou "dobrar a costa"”.

Por todo o exposto, denota-se que existia um temor dos navegadores nas viagens marítimas. Portanto, podemos frisar aqui o sentido do Bojador cujo qual é salientado no poema de Pessoa - que retrata que quem passar pelo Bojador também terá de passar pela dor.

O Cabo Bojador, no território do Sara Ocidental e em frente às ilhas Canárias, era, na época, considerado inultrapassável pelos europeus. De facto, o Cabo Bojador era um ponto traiçoeiro, por causa das correntes e dos ventos. A cinco quilómetros da costa do cabo, a profundidade em alto mar chega a ser de apenas dois metros, devido provavelmente ao assoreamento provocado por milhares de anos de tempestades de areia sopradas do deserto do Sara. Entretanto, a "corrente das Canárias" contém fortes redemoinhos e ondas altas, correndo perpendicularmente às falésias da costa sobre recifes de arestas pontiagudas, tornando a navegação muito arriscada. Além disso, o regime de ventos e correntes torna difícil o regresso para Norte junto à costa. (SIQUEIRA, 2015, s.p.).

Alguns documentos relatam essa história de medo e angustia que foi a travessia pelo Cabo Bojador. Como exemplo, a dissertação "Rumos da história contada pelos quinhentistas portugueses" da autora Luciana Fontes Parzewski. Esta pesquisa histórica nos mostra fragmentos de como essas viagens épicas marcaram com a dor a vida desses navegadores.

Essas viagens iniciais causaram inquietação não só por parte dos mareantes, entre os quais era dito o provérbio "quem passar o cabo (Bojador) de nau, ou tornará ou não", mas também por parte da população, porque a gente que saía nos navios deixava "muitos órfãos e viúvas no reino, além das despesas de suas fazendas, pois o perigo e os gastos ambos eram manifestos e o proveito tão incerto como todos". Esse medo que cercava as viagens deixava "o coração de todos (...) entre prazer e lágrimas. Era grande dúvida qual seria o primeiro que quisesse pôr sua vida em semelhante aventura. (PARZEWSKI, 2007, p.16) 
Sabemos que pelo Bojador ocorreram muitas tentativas não bem-sucedidas como afirma o autor Cuyverss (1998) que destaca que o historiador Damião Peres, ao estudar uma carta régia do século XV, relatou ter encontrado que foram realizadas 15 tentativas em 12 anos, nenhuma e que nenhuma teria sido capaz de vencer o cabo Bojador. Até o ano de 1434. Ou seja, assim quando Gil Eanes ${ }^{3}$ conseguiu cumprir a perigosa travessia.

Ao navegar por "mares nunca dante navegados" (CAMÕES, 2002, p.202), os portugueses defrontaram-se com dificuldades que até então eram desconhecidas, além do próprio mar, obstáculo a sobrevivência dos marinheiros e àqueles que suas vidas arriscavam na passagem, as incertezas de uma terra desconhecida e dos povos que nelas habitavam.

Como no próprio poema de Luiz de Camões, Os Lusíadas, a dificuldade era já conhecida pela sociedade a época da publicação de seu livro, estimado em 1572. Os cantos destacam as dificuldades, as tormentas, as incertezas e a luta pela sobrevivência dos que nessa viagem haviam embarcado.

Essas histórias caracterizadas pelos poemas e crônicas da época, marcam os acontecimentos, como histórias de medo e coragem - como o Bojador de Fernando Pessoa. Hoje no contexto atual ouvimos o medo dos sírios contra os perigos do Mar Mediterrâneo.

O que descreveremos nas próximas linhas, decorre de uma nova história. "Outra" história de dificuldades, dor, medo e lágrimas salgadas que se escreveu num tempo e espaço diferente. A triste história da travessia pelo Mar Mediterrâneo - pelo mar traiçoeiro - marcada pelas dificuldades, através da qual sírios buscam refúgio e asilo político em países da Europa Ocidental.

O Mar Mediterrâneo tem se tornado a rota de travessia para os países europeus, sendo a Líbia uma das principais portas de saída pela proximidade com a Itália e Grécia. Este fluxo migratório vem ocorrendo nos últimos anos devido a uma guerra civil na Síria que se principiou em março de 2010 no âmbito da "Primavera Árabe".

Entretanto, assistimos veiculado na mídia a faceta de uma das maiores histórias sobre o tráfico humano de pessoas. As elegantes caravelas foram trocadas por botes e embarcações superlotadas sem o mínimo de segurança e que segundo fonte, (site G1.globo) este seria um negócio milionário.

A travessia do Mediterrâneo é feita em botes ou em embarcações superlotadas, sem os mínimos requisitos de segurança, por traficantes de pessoas. A viagem pode custar mais de R\$ 10 mil por pessoa, o que torna o negócio altamente lucrativo - uma única embarcação pode render US\$ 1 milhão. Sem garantia de sucesso no pedido de refúgio, muitos imigrantes não conseguem ficar no destino final e são mandados de volta ao país de origem. Mas dificilmente eles desistem e tentam duas, três, quatro vezes, até receberem o asilo oficial. (G1.globo, 2015, s.p.) 
As viagens marítimas no mediterrâneo têm causado muitas mortes - a dos sírios que se aventuraram em busca de segurança na Europa - pessoas sendo dragadas pelo traiçoeiro mar, em razão de naufrágios das embarcações.

Outubro de 2013: cerca de 360 pessoas morreram em naufrágio próximo à ilha de Lampedusa, Itália. Setembro de 2014: pelo menos 300 imigrantes naufragaram em Malta, quando traficantes fizeram um "assassinato em massa" depois que as pessoas se recusaram a mudar para uma embarcação menor. Fevereiro de 2015: pelo menos 300 imigrantes teriam se afogado quando 4 botes entraram em apuros depois de deixarem a Costa da Líbia com condições climáticas ruins. Abril de 2015: cerca de 400 imigrantes se afogaram quando o barco deles virou na costa da Líbia. Abril de 2015: cerca de 700 imigrantes teriam se afogado após o barco ter virado próximo à Lampedusa. (G1.globo, 2015, s.p.)

Estamos vivendo um momento distinto de migração, e as dificuldades que se revelaram no poema Mar Português de Fernando Pessoa se repetem, porém de forma mais drástica no Mar Mediterrâneo atualmente.

\section{CONCLUSÃO}

No início deste artigo, foi afirmado que faríamos uma comparação do poema "Mar Português" de Fernando Pessoa com a diáspora síria que acontece atualmente pelo Mar Mediterrâneo. Sendo assim, reconhecemos que nesta comparação a presença da dor física e emocional está fortemente marcada nestas duas histórias distintas de navegações.

Primeiramente se faz necessário observar que no início do desenvolvimento deste trabalho, quando mencionamos "mar à vista" fazemos alusão a experiências dolorosas que famílias - portuguesas e sírias - tem se submetido. O mar que contempla a vista das pessoas seria um mar de lágrimas. "Ó mar salgado, quanto do teu sal, são lágrimas de Portugal! Um mar de lágrimas que portugueses se submeteram na busca de novas possibilidades comerciais, um mar de lágrimas que os sírios foram submetidos na busca de novas possibilidades de vida.

Dentro desse contexto, analisamos na segunda estrofe "Quantas noivas ficaram por casar, Para que fosses nosso, ó mar! O sofrimento infligido a uma família imigrante - a vida prematura que se foi perdida - tal como muitas portuguesas nos séculos XV e XVI, tentando abrir os olhos para os direitos humanos negligenciados desses refugiados, que em uma nova crise internacional fixa mais uma diáspora.

Reconhece-se também que a dor foi marcada fisicamente na vida desses viajantes devido as baixas condições das embarcações, sejam elas por falta de tecnologia como no caso das caravelas ou por falta de infraestrutura como nos botes. No texto "Mar traiçoeiro" ficou 
assaz demonstrado que navegadores deixaram registrados nos seus diários de viagens o medo e a dor física que sentiam durante a travessia com as caravelas portuguesas que afundavam no Cabo Bojador. Da mesma forma está registrado nas mídias atuais e smartphones a dor dos viajantes sírios que devido a sua diáspora forçada, sofrem da mesma dor e medo, devido as possibilidades de morte nas péssimas condições das embarcações quais são submetidos.

Por todo o exposto refletimos que diante das análises traçadas e as semelhanças encontradas entre o poema e a realidade que aflige quase em sua totalidade o povo sírio, encontramo-nos novamente diante de uma grande crise mundial. Crise esta, que não só lança ao mar a sorte, muitas vezes tragando para o fundo do mar filhos, pais e esposas, mas que apresenta uma degradação da sociedade que diante de uma tragédia repetida, novamente encontra-se em conflito e muito tarda a resolver.

O poeta Walt Whitman, em uma de suas obras versa sobre os heróis, aqueles que muitas vezes se arriscam e que nem sempre se tornam reconhecidos. Desta forma, optamos em trazê-lo para recordar que o grande valor da travessia, está na coragem de enfrentar os desafios, nem sempre bem sucedidos, mas aos que optaram em não se entregar e a buscar algo melhor.

\author{
Eu rufo e bato o tambor pelos mortos \\ e sopro minhas embocaduras \\ o que de mais alto e mais jubiloso \\ posso por eles. \\ Vivas àqueles que levaram a pior! \\ E àqueles cujos navios de guerra \\ afundaram no mar! \\ E a todos os generais \\ das estratégias perdidas, \\ que foram todos heróis! \\ E ao sem número de heróis maiores \\ que se conhecem!
}

(WHITMAN,1984, p.30)

\title{
NOTAS
}

1 Apesar de muitas vezes ser utilizado apenas em referência aos povos judaicos exilados da Babilônia e pós-destruição de Jerusalém, no ano de 70 D.C., em muitas situações a migração massiva de Portugal e posteriormente do povo português de suas colônias, pode ser considerada uma diáspora portuguesa, espalhando pelo mundo, quase metade do total de sua população pelos muitos países, sem contar as novas gerações originárias dessa expansão

2 Os rebeldes sírios, também conhecidos como Coalizão Nacional Síria da Oposição e das Forças Revolucionárias, é um grupo formado por políticos, ativistas, militares e que representa uma coalizão contra o governo do ditador Bashar Al-Assad. 
3 Gil Eanes foi um navegador português escudeiro do Infante D. Henrique, cuja biografia permanece ainda pouco conhecida. Foi o primeiro a navegar para além do Cabo Bojador, em 1434.

4 Primavera Árabe foi uma insurreição das populações de países árabes como Síria, Tunísia, Líbia e Egito as quais se revoltaram contra os governos de seus países.

\section{REFERÊNCIAS}

AFP. Mais de 380 mil imigrantes chegaram à Europa pelo Mediterrâneo em 2015. G1. São Paulo, 08 set. 2015. Disponível em: <http:/g1.globo.com/mundo/noticia/2015/09/mais-de-380mil-refugiados-chegaram-europa-pelo-mediterraneo-em-2015.html >. Acesso em: 28 set. 2015.

$\mathrm{BBC}$. Os países que mais recebem refugiados sírios. BBC. London, set. 2015. Disponível em: $<\mathrm{http}$ //www.bbc.com/portuguese/noticias/2015/09/150910_vizinhos_refugiados_lk>. Acesso em: 27 set. 2015.

CAMÕES, Luís Vaz. Os Lusíadas. São Paulo: Martin Claret, 2002.

CUYVERS, Luc. Na rota do Oriente: A Barreira do Medo. Mare Nostrum, 1998 disponível em: http://ensina.rtp.pt/artigo/gil-eanes-dobra-o-cabo-bojador/Acesso em: 28 set. 2015.

D’ÉLIA, Karla Alessandra de Amorim. Uma Abordagem Psicológica Sobre o Medo. Psicologado, out. 2013. Disponível em: <https://psicologado.com/atuacao/psicologia-clinica/ uma-abordagem-psicologica-sobre-o-medo> Acesso em: 28 set. 2015.

DIEGUES, Antônio Carlos Sant'Ana. Povos e Mares: uma retrospectiva de sócio-antropologia marítima. São Paulo: CEMAR, Centro de Culturas Marítimas, Universidade de São Paulo, 1993.

FONSECA, Luís Adão. O imaginário dos navegantes portugueses dos séculos 15 e 16. Estudos Avançados 6 (16), 1992. Disponível em: <http://www.scielo.br/scielo.php?script=s ci_arttext\&pid=S0103-40141992000300004

FONSECA, Sérgio Roxo da. Fernando Pessoa e o bojador. Academus. 2006, set. 2015. Disponível em: $<\mathrm{http}: / \mathrm{www}$.academus.pro.br/site/pg.asp?pagina $=$ detalhe_variedade $\&$ titulo $=\mathrm{Va}$ riedades $\&$ codigo $=156 \&$ cod_categoria $=\&$ nome_categoria $>$. Acesso em: 28 set. 2015

DECLARAÇÃO UNIVERSAL DOS DIREITOS DO HOM EM. Disponível em: <http:/ / www.onu-brasil.org.br/ documentos_direitoshumanos.php>. Acesso em: 03 de out de 2015.

PARZEWSKI, Luciana Fontes. Rumos da história contada pelos quinhentistas portugueses. 2007. 124 f. Dissertação (Mestrado) - Curso de História e Cultura Social, Universidade Estadual Paulista Júlio de Mesquita Filho, Franca, 2007.

SILVA, Janice Theodoro da. Descobrimentos e Colonização. $2^{\mathrm{a}}$ ed. São Paulo: Ed. Ática, 1989. Série Princípios.

SHIRER, William. Ascensão e Queda do Terceiro Reich (4 vols). Editora Civilização Brasileira S.A. Rio de Janeiro, 1964. 
SIQUEIRA, Jairo. A passagem do Cabo do Medo. 2012. Disponível em: $<$ http://criatividadeaplicada.com/2012/01/22/a-passagem-do-cabo-do-medo/>. Acesso em: 20 set. 2015.

TENGARRINHA, José (org). História de Portugal. $2^{\mathrm{a}}$ ed. Bauru, SP: EDUSC, 2001.

WHITMAN, Walt. Folhas de Relva. São Paulo: Editora Brasiliense S.A., 1984. 